\title{
Effectiveness of Nifedipine Compared to Vaginal Progesterone in Treatment of Threatened Preterm Birth
}

\author{
M.K.Alloush, A.S.Ebrahem, M.A.Mahmoud, D.E.Ali and Y.M.Abdelzaher \\ Obstetrics and Gynaecology, Dept., Faculty of Medicine, Benha Univ., Benha, Egypt \\ E-mail:doaa123@yahoo.com
}

\begin{abstract}
Public health officials and obstetricians alike want to avoid premature delivery wherever possible. Pregnant women at high risk of preterm labour may have been the most effective method of preventing preterm labour. Pharmacological therapy with a variety of drugs has been the primary method for managing acute preterm labour. The primary goal of this research is to assess the effectiveness, success rate, and outcomes for both the mother and the baby with progesterone and nifedipine given to women at risk of preterm delivery as tocolytic medications. Benha University Hospital and Belbeis Central Hospital chose patients from the inpatient clinics of the Obstetrics \& Gynaecology Department. For four doses of intramuscular dexamethasone, all patients received injections of $6 \mathrm{mg}$ intramuscularly every 12 hours. Two groups of 60 participants each were included in the prospective comparative interventional trial, with 10 patients being lost to follow-up. nifedipine $20 \mathrm{mg}$ orally every 12 hours from diagnosis until 34 weeks was given to thirty pregnant women with imminent preterm delivery in the form of a $20 \mathrm{mg}$ tablet. Group II: Thirty patients received $400 \mathrm{mg}$ micronized progesterone vaginally at admission time and once at bedtime for the first 48 hours of treatment. 30 women got nifedipine with gestational age (median 30 weeks), 30 received progesterone with gestational age (median 31 weeks), and the patients who were originally recruited had successful acute tocolysis with nifedipine. We found that nifedipine was more often associated with side effects than progesterone in our study. No one in our study had to discontinue taking their medication due to adverse effects or intolerance. However, Females in the nifedipine group reported feeling drowsy 16.7 percent of the time, compared to none in the progesterone group. Researchers did not find any evidence of nausea (10\%), sadness (3.33\%), or Git symptoms (3.33\%) among the niedipine side effects studied.
\end{abstract}

Keywords: Nifedipine, Vaginal Progesterone, Preterm Birth.

\section{Introduction}

Unplanned pregnancies are a primary source of neonatal illness and death, as well as short and longterm impacts on a child's brain development. $12 \%$ of all pregnancies result in a premature delivery. There has been a $27 \%$ rise over ten years in preterm birth, which accounts for $85 \%$ of all perinatal morbidity and mortality [21].

When labour occurs after viability but before the 37 th week of pregnancy, it is considered premature labour by the World Health Organization (WHO). The onset of labour is influenced by a variety of factors, including the presence of recorded uterine contractions (at least one per 10 minutes), ruptured foetal membranes, a documented cervical change of $1 \mathrm{~cm}$ or less, and/or a cervical dilation more than $2 \mathrm{~cm}$. There may be uterine contractions but no cervical changes if premature labour is a risk [15].

A pregnant woman is considered to be in danger of preterm labour if she has at least three contractions every 10 minutes between the ages of 20 and 37 weeks, but the cervix has not yet effaced or dilated. As a result, the test's completion time was at least 30 minutes [4].

It is desirable to utilise calcium channel blockers because of the ease and low cost of taking them orally, as well as the possible usefulness in reducing neonatal mortality (as shown in one major piece of research). The safe and effective use of Nifedipine as a therapy for acute tocolysis with minimal side effects has also been shown in recent years. When utilised for longterm tocolysis, however, the results have been inconsistent. Uterine quiescence necessitates the hormone progesterone. For women at high risk of preterm childbirth, as well as for long-term tocolysis, it's becoming increasingly prevalent. To our knowledge, nifedipine and progesterone have not been compared for the maintenance of tocolysis [12].

As a common tocolytic medicine, the drug nifedipine seems to be more effective in combination with magnesium sulphate than with magnesium sulphate alone. Treatment options included progesterone and bed rest. Premature labour may be treated with nifedipine, the first-line tocolytic drug. On the other hand, the effectiveness of nifedipine in cases of imminent preterm labour has not been adequately studied [23].

The incidence of premature birth was decreased by 44 percent in a randomised study of vaginal progesterone capsules for the short cervix (defined as $15 \mathrm{~mm}$ or less): RR 0.56 ; $95 \%$ CI $0.36-0.86$; p 0.001 . It did not, however, seem to be linked to an improvement in newborn results [19].

Most current guidelines recommend a 48-hour course of prenatal corticosteroids for women with threatening preterm birth discovered before 34 weeks of pregnancy; tocolytic therapy is routinely provided for 48 hours in the majority of countries to allow administration of corticosteroids; however, there are exceptions [14].

Progesterone and nifedipine were tested as tocolytic medications in women who were at risk of preterm birth to see whether they had any influence on 
efficacy, success, and the effects on the mother and foetus.

\section{Patients and Methods}

A prospective comparative interventional study. The patients were selected from those attending the inpatient Clinic of the Obstetrics \& Gynaecology Department, Benha University Hospital, and Belbeis central hospital. It was done from April 2019: December 2019.

All patients received injection dexamethasone 6 m.g intramuscular 12 hours for four doses to affect fetal lung maturity.

This study was divided into two groups:

- Group I: Thirty pregnant women with imminent preterm delivery got the initial nifedipine dosage in the form of a $20 \mathrm{mg}$ pill orally every 30 minutes for three times, then a maintenance dose of nifedipine $20 \mathrm{mg}$ every 12 hours from assessment until 34 weeks.

- Group II: Thirty patients have received 400mg micronized progesterone vaginally at admission time and then once at bedtime for the first 48hours.

\section{Inclusions criteria}

- Age between 20- 35 years.

- Gestational age between 28-34 weeks.

- Pregnant women with threatened preterm labor regular painful uterine contractions (3 in 10 minutes)

- Intact membrane.

- Without cervical changes $(<3 \mathrm{~cm})$.

- Single normal fetus with cephalic presentation

Exclusion criteria

- Antepartum hemorrhage.

- Lethal fetal anomaly.

- IUGR.

- Cerclage.

- Multiple pregnancies.

- Cervical dilatation more than $3 \mathrm{~cm}$.

- Chorioamnionitis and ruptured membranes.
- Patients with severe diabetes mellitus, preeclampsi

- a, hepatic and renal diseases.

- Nifedipine allergy.

\section{Methods}

All patients were subjected to the following

- Written informed consent.

- Detailed history including

- Personal history, menstrual history, previous obstetric history, previous preterm deliveries, gestational age, past history, family history, history of drug intake.

\section{Examination}

- Complete general examination to exclude any medical disorder with close observation to pulse, blood pressure.

- Abdominal examination to detect the presence of uterine contraction.

- Local examination or vaginal examination to detect any cervical changes.

\section{Investigation}

The routine investigations were done for all pregnant women (CBC-RBS-RH-ABO-Coagulations Profile-Liver, Renal function tests-Routine urine analysis).

Abdominal ultrasound was done for gestational age, presentation of fetus, numbers of the fetus, amounts of liquor exclude congenital anomalies, placental location, appearances, exclude any placental abruption, placenta praevia.

\section{Statistical analysis}

Key results will be tabulated and analyzed by suitable statistical methods using the computer program (SPSS).

\section{Results}

This study included 60 patients. Thirty groups received progesterone (group I), and thirty groups received Nifedipine (group II)

Table (1) Distribution of demographic data of the studied groups.

\begin{tabular}{lcccc}
\hline Demographic Data & $\begin{array}{c}\text { Nifedipine } \\
(\mathbf{N}=\mathbf{3 0})\end{array}$ & $\begin{array}{c}\text { Progesterone } \\
(\mathbf{N}=\mathbf{3 0})\end{array}$ & $\begin{array}{c}\text { Mann-Whitney } \\
\text { test }\end{array}$ & P-value \\
\hline $\begin{array}{l}\text { Parity } \\
\text { Median }\end{array}$ & 1.92 & 2.00 & 257.500 & $0.122 \mathrm{~ns}$ \\
$\begin{array}{l}\text { Q. R) } \\
\text { Weight }\end{array}$ & $0.00-2.25$ & $1.75-3.00$ & & \\
Median & & & & \\
(I.Q.R) & 79.5 & 80.5 & 369.6 & $0.254 \mathrm{~ns}$ \\
BMI & $71.25-80.6$ & $73.5-84.1$ & & \\
$\begin{array}{l}\text { Median } \\
\text { (I.Q.R) }\end{array}$ & 31.5 & 32.6 & 341.22 & $0.142 \mathrm{~ns}$ \\
\hline
\end{tabular}

$\mathrm{Ns}$; indicate as non-significant at $\mathrm{p}$ value $>0.05$; I.Q.R; interquartile range

At a p-value $>0.05$, there is no statistically significant difference between nifedipine and progesterone in maternal age, gestational age, parity, weight, or BMI. (Table 1, Figure 1,2). 


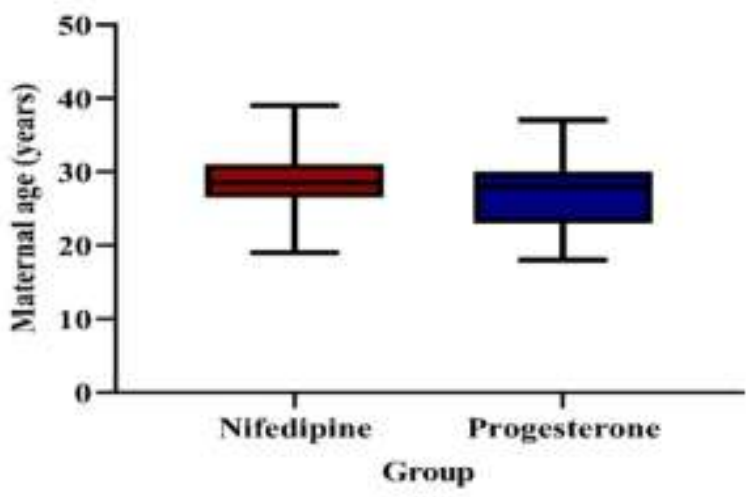

Fig. (1) Box plot show comparison between Nifedipine and Progesterone regarding maternal age

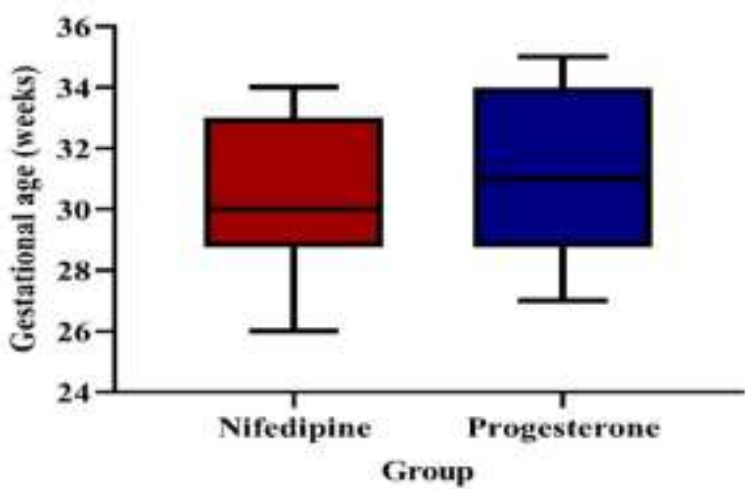

Fig. (2) Box plot shows a comparison between Nifedipine and Progesterone regarding Gestational age.

Table (2) General examination on the admission of the studied groups.

\begin{tabular}{lcccc}
\hline $\begin{array}{l}\text { General } \\
\text { examination }\end{array}$ & $\begin{array}{c}\text { Nifedipine } \\
(\mathbf{N}=\mathbf{3 0})\end{array}$ & $\begin{array}{c}\text { Progesterone } \\
(\mathbf{N}=\mathbf{3 0})\end{array}$ & $\begin{array}{c}\text { Test of } \\
\text { significance }\end{array}$ & P-value \\
\hline $\begin{array}{l}\text { Maternal median } \\
\text { blood pressure }\end{array}$ & 79 & 80.00 & $272.022^{*}$ & $0.242 \mathrm{~ns}$ \\
$\begin{array}{l}\text { Median } \\
\text { (I.Q. R) }\end{array}$ & $70-80$ & $74-84$ & & \\
$\begin{array}{l}\text { F.R.H (BEATS/M) } \\
\text { Median }\end{array}$ & 138.00 & & & \\
$\begin{array}{l}\text { I.Q. R) } \\
\text { Pulse (BEATS/M) }\end{array}$ & $135-142$ & $136.75-140$ & $297.00 *$ & $0.093 \mathrm{~ns}$ \\
Mean \pm SD & $70.8 \pm 6.22$ & $72.6 \pm 5.41$ & & \\
\hline
\end{tabular}

$\mathrm{Ns}=$ non significant at $\mathrm{p}$ value $>0.05$, \#; t test. I.Q.R = interquartile range, *; Mann Whitney test,

At a p-value $>0.05$, there is no statistically significant difference between nifedipine and progesterone in maternal median blood pressure, F.R.H, and pulse (Table 2).

Table (3) General examination of the studied groups after $30 \mathrm{~min}$.

\begin{tabular}{lcccc}
\hline $\begin{array}{l}\text { General } \\
\text { examination }\end{array}$ & $\begin{array}{c}\text { Nifedipine } \\
(\mathbf{N}=\mathbf{3 0})\end{array}$ & $\begin{array}{c}\text { Progesterone } \\
(\mathbf{N}=\mathbf{3 0})\end{array}$ & Mann whitny test & P-value \\
\hline $\begin{array}{l}\text { Maternal median } \\
\text { blood pressure }\end{array}$ & & & & \\
$\begin{array}{l}\text { Median } \\
\text { (I.Q. R) }\end{array}$ & 70.00 & 80.00 & 249.00 & $0.002 \mathrm{~S}$ \\
\hline
\end{tabular}

$\mathrm{S}=$ significant at $\mathrm{p}$ value $<0.05 ;, \mathrm{Ns}=$ non significant at $\mathrm{p}$ value $>0.05, \mathrm{HS}=$ Highly significant at $\mathrm{p}$ value $<0.001$, I.Q.R= interquartile range

Table 3 shows a statistically significant difference between Nifedipine and Progesterone regarding maternal median blood pressure and pulse p-value $<0.05$. While the no statistical difference between Nifedipine and Progesterone regarding F.R.H (Table 3, Figures 3-4). 


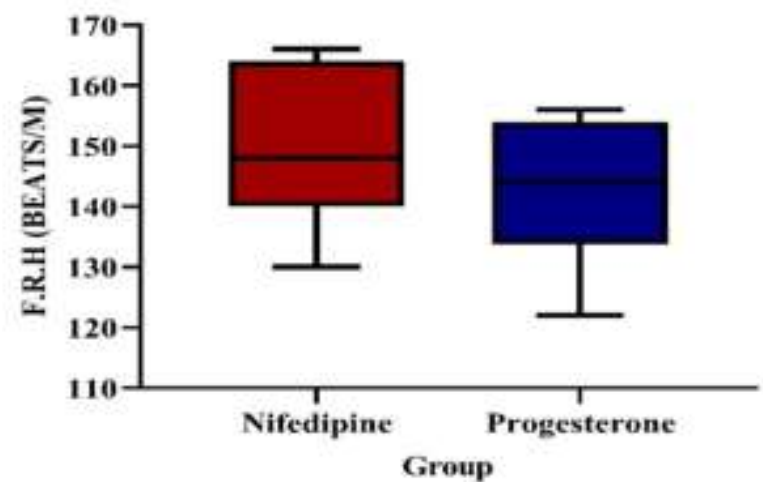

Fig. (3) Box plot shows a comparison between Nifedipine and Progesterone regarding FRH.

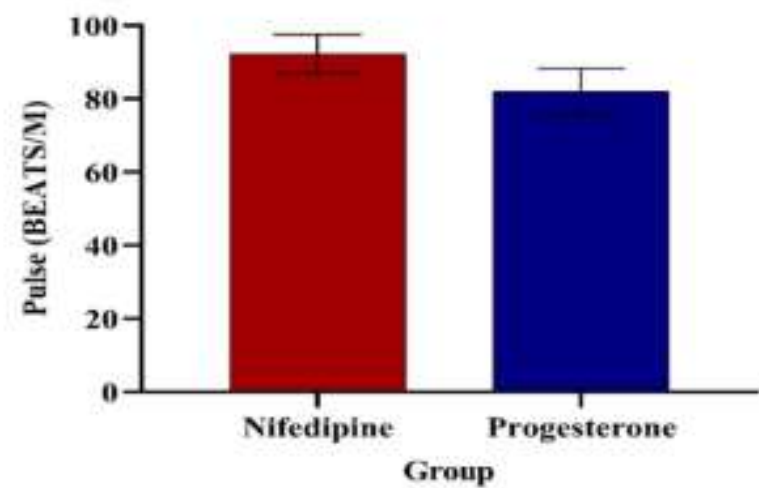

Fig. (4) Box plot shows a comparison between Nifedipine and Progesterone regarding pulse.

Table (4) Comparison between the efficacy of the studied methods of treatments on admission.

\begin{tabular}{lcccccc}
\hline Variable & \multicolumn{2}{c}{$\begin{array}{c}\text { Nifedipine } \\
(\mathbf{N = 3 0})\end{array}$} & \multicolumn{2}{c}{$\begin{array}{c}\text { Progesterone } \\
(\mathbf{N = 3 0})\end{array}$} & Chisquare & P-value \\
& No & $\%$ & No & $\%$ & & \\
\hline $\begin{array}{l}\text { Uterine contraction } \\
\text { Stopped }\end{array}$ & 19 & 63.3 & 23 & 76.7 & 1.270 & $0.260 \mathrm{~ns}$ \\
$\begin{array}{l}\text { Not stopped } \\
\text { Cervical change }\end{array}$ & 11 & 36.7 & 7 & 23.3 & & \\
-ve & 16 & 53.3 & 19 & 63.3 & 0.617 & $0.432 \mathrm{~ns}$ \\
+ +ve & 14 & 46.7 & 11 & 36.7 & & \\
\hline
\end{tabular}

Ns= non significant at $p$ value $>0.05$

Table 4 reveals no statistically significant difference in uterine contraction and cervical change on admission between nifedipine and progesterone ( $\mathrm{p}$-value $>0.05)$.

Table (5) Comparison between the efficacy of the studied methods of treatments after $48 \mathrm{~h}$

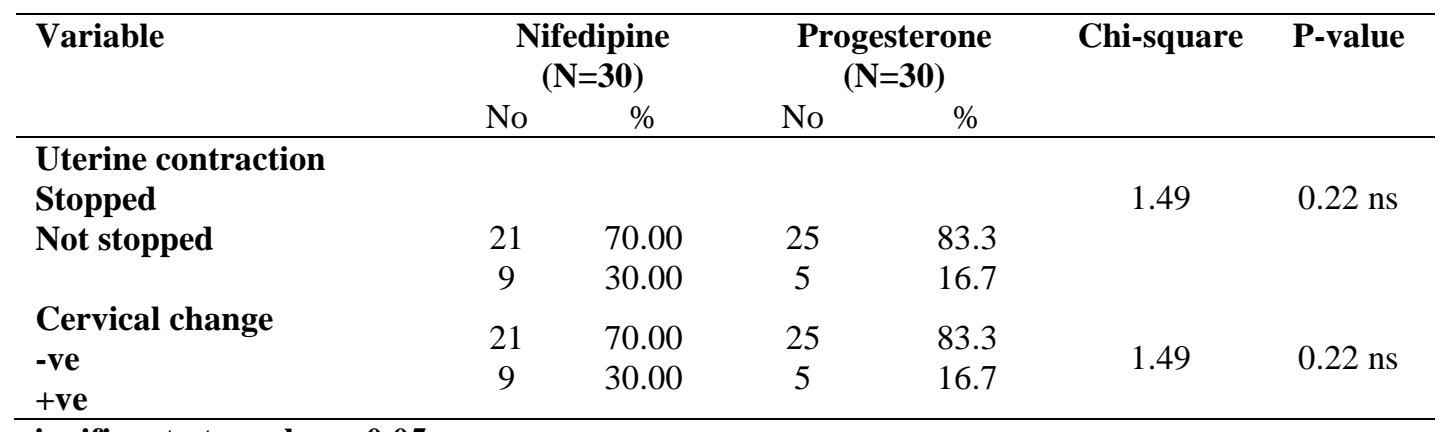

Ns= non significant at $p$ value $>0.05$

In terms of the uterine contraction and cervical change at 48 hours, Table 5 reveals no statistically significant difference between nifedipine and progesterone, $\mathrm{p}$-value $>0.05$. 
Table (6) Comparison between the side effect of the studied methods of treatments.

\begin{tabular}{|c|c|c|c|c|c|c|}
\hline \multirow[t]{2}{*}{ Variable } & \multicolumn{2}{|c|}{$\begin{array}{l}\text { Nifedipine } \\
(\mathbf{N}=30)\end{array}$} & \multicolumn{2}{|c|}{$\begin{array}{c}\text { Progesterone } \\
(\mathrm{N}=30)\end{array}$} & \multirow[t]{2}{*}{ Chi-square } & \multirow[t]{2}{*}{ P-value } \\
\hline & No & $\%$ & No & $\%$ & & \\
\hline \multicolumn{7}{|l|}{ Side effect } \\
\hline No & 16 & 53.3 & 24 & 80.0 & 4.80 & $0.028 \mathrm{~S}$ \\
\hline Yes & 14 & 46.7 & 6 & 20.0 & & \\
\hline
\end{tabular}

$\mathrm{S}=$ significant at $\mathrm{p}$ value $<\mathbf{0 . 0 5}$

Table 6 reveals a statistically significant difference in side effects between nifedipine and progesterone $(\mathrm{p}$-value < $0.05)$.

Table (7) Distribution of side effects of the two methods of treatment.

\begin{tabular}{lcccccc}
\hline Variable & \multicolumn{2}{c}{$\begin{array}{c}\text { Nifedipine } \\
(\mathbf{N}=\mathbf{3 0})\end{array}$} & \multicolumn{2}{c}{$\begin{array}{c}\text { Progesterone } \\
(\mathbf{N}=\mathbf{3 0})\end{array}$} & Chi-square & P-value \\
\hline NO & $\mathbf{N o}$ & $\mathbf{\%}$ & $\mathbf{N o}$ & $\mathbf{\%}$ & & \\
Nausea & 10 & 33.3 & 22 & 73.36 & & \\
Abdominal pain & 5 & 16.7 & 4 & 13.33 & & \\
Flushing & 4 & 6.06 & 4 & 13.33 & 15.611 & $0.004 \mathrm{~S}$ \\
Drowsing & 3 & 10.0 & 0 & 0.0 & & \\
\hline
\end{tabular}

$\mathrm{S}=$ significant at $\mathrm{p}$ value $<0.05$

Table 7 reveals a statistically significant difference in side effects between nifedipine and progesterone.

Table (8) Comparison between groups regarding Mode of delivery, Parity gestational age at delivery

\begin{tabular}{|c|c|c|c|c|c|c|}
\hline \multirow[t]{2}{*}{ Neonatal } & \multicolumn{2}{|c|}{$\begin{array}{l}\text { Nifedipine } \\
(\mathbf{N}=30)\end{array}$} & \multicolumn{2}{|c|}{$\begin{array}{c}\text { Progesterone } \\
(\mathrm{N}=30)\end{array}$} & \multirow[t]{2}{*}{ Chi-square } & \multirow[t]{2}{*}{ P-value } \\
\hline & No & $\%$ & No & $\%$ & & \\
\hline Mode of delivery & & & 2 & & & \\
\hline C.S & 19 & 63.3 & 0 & 66.7 & 0.073 & $0.787 \mathrm{~ns}$ \\
\hline Vaginal delivery & 11 & 36.7 & 10 & 33.3 & & \\
\hline \multicolumn{7}{|c|}{ Parity gestational age at delivery } \\
\hline 37 weeks & 20 & 66.7 & 25 & 83.3 & 2.22 & $0.163 \mathrm{~ns}$ \\
\hline$<37$ weeks & 10 & 33.3 & 5 & 16.7 & & \\
\hline
\end{tabular}

Ns= non significant at $p$ value $>0.05$

In terms of mode of delivery, parity, and gestational age at delivery, table 8 demonstrates no statistically significant difference between nifedipine and progesterone.

Table (9) Comparison between groups regarding Neonatal respiratory distress, Neonatal ICU admission.

\begin{tabular}{|c|c|c|c|c|c|c|}
\hline \multirow[t]{2}{*}{ Variable } & \multicolumn{2}{|c|}{$\begin{array}{l}\text { Nifedipine } \\
(\mathbf{N}=\mathbf{3 0})\end{array}$} & \multicolumn{2}{|c|}{$\begin{array}{l}\text { Progesterone } \\
\quad(\mathbf{N}=30)\end{array}$} & \multirow[t]{2}{*}{ Chi-square } & \multirow[t]{2}{*}{ P-value } \\
\hline & No & $\%$ & No & $\%$ & & \\
\hline Neonatal respiratory distress & & & & & 0.082 & $0.774 \mathrm{~ns}$ \\
\hline Present & 8 & 26.7 & 9 & 30.00 & & \\
\hline Absent & 22 & 73.3 & 21 & 70.00 & & \\
\hline Neonatal ICU admission & & & & & 0.082 & $0.774 \mathrm{~ns}$ \\
\hline Present & 8 & 26.7 & 9 & 30.00 & & \\
\hline Absent & 22 & 73.3 & 21 & 70.00 & & \\
\hline
\end{tabular}

Ns= non significant at $p$ value $>0.05$

Table 9 demonstrates that at a p-value $>0.05$, there is no statistically significant difference between nifedipine and progesterone in terms of infant respiratory distress and neonatal ICU hospitalization.

Table (10) Comparison between groups regarding Neonatal birth weight.

\begin{tabular}{lcccc}
\hline Neonatal & $\begin{array}{c}\text { Nifedipine } \\
(\mathbf{N}=\mathbf{3 0})\end{array}$ & $\begin{array}{c}\text { Progesterone } \\
(\mathbf{N}=\mathbf{3 0})\end{array}$ & $\begin{array}{c}\text { Mann Whitney } \\
\text { test }\end{array}$ & P-value \\
\hline $\begin{array}{l}\text { Neonatal birth weight } \\
\text { Median }\end{array}$ & 2.5 & 2.5 & 383.50 & $0.322 \mathrm{~ns}$ \\
(I.Q.R) & $2.0-3.0$ & $2.3-3.0$ & & \\
\hline
\end{tabular}

$\mathrm{Ns}=$ non significant at $\mathrm{p}$ value $>0.05$

In terms of neonatal birth weight, this data reveals no statistically significant difference between nifedipine and progesterone. 


\section{Discussion}

Public health officials and obstetricians alike want to avoid premature delivery wherever possible. Primary prevention is desirable, but not always possible, due to the etiology's complexity and lack of understanding. Preterm labour may be prevented by identifying pregnant women who are at high risk of preterm delivery early on. Every intervention must delay or prevent premature delivery and improve outcomes for newborns if it is to be effective in reducing preterm birth concerns. Pharmacological therapy with a variety of drugs has been the primary method for managing acute preterm labour. The use of maintenance tocolysis is required in individuals who have had preterm labour recurrences since they are at a greater risk. Nifedipine is currently our preferred medicine for both acute and long-term tocolysis because of its safety and ease of administration.

Using a p-value of 0.258 , no difference was found between the 30 women who got nifedipine at 30 weeks of gestation or the 30 women who received progesterone at 31 weeks of gestation. Thus, our research is supported by these investigations. Nifedipine and progesterone have been shown by [21], [19], and [12] to have no effect on each other.

Current research showed statistically significant variations in maternal blood pressure $(\mathrm{mmHg})$ and pulse rate among study participants. Mean maternal blood pressure was found to be statistically significant across groups according to A.Shumaila et al [22]. Moreover, According to Abdel Hak and Gafaar et al., a clinically negligible drop in maternal heart rate was identified during hemodynamic testing in contrast to our findings.

In the group on nifedipine, $16 \%$ of women had hypotension. Reflex tachycardia was also reported after 20 minutes of oral nifedipine administration, according to DJ.Lyell et al.[13]. Diastolic blood pressure fell by an average of $11 \%$.

The frequency of uterine contractions is not significantly different between the two groups. S.Kamat et al. [12] observed no significant differences in sociodemographic characteristics or clinical characteristics between the two groups when comparing the effectiveness and safety of nifedipine with or without vaginal progesterone for acute tocolysis in premature labour. A wide range of tocolytic medications are now used to treat premature labour.

Maintaining tocolysis for preterm labour women should be done using calcium channel blockers rather than beta-mimetic tocolytics. However, new study has put doubt on the efficacy of nifedipine as a long-term tocolytic in the treatment of cancer [13].

Nifedipine was employed in this study to effectively induce acute tocolysis in the originally recruited participants. nifedipine was also beneficial in decreasing the risk of a premature birth. Nifedipine has been shown to be effective in the treatment of acute tocolysis in several previous studies [6,21].
Premature labour may be prevented by administering progesterone, which has long been recognised to have a role in uterine quiescence. Despite this, the precise mechanism by which progesterone prolongs pregnancy is still not known.. Changes myometrium levels; relaxes myometrial smooth muscles; inhibits the establishment of gap junctions; and prevents the impact of oxytocin from occurring. Prostaglandin-stimulating effects of oestrogen are countered by the reduction of myometrial oxytocin receptors [20].

Progesterone and nifedipine groups showed no statistically significant differences in cervical alterations in the present investigation. There was no significant difference in cervical alteration or effacement between the nifedipine and progesterone groups at admission, as reported by S.Kamat and colleagues [12]. EB.Fonseca et al.,[9], on the other hand, found that progesterone therapy lowers the incidence of spontaneous early preterm birth in women with a short cervix compared to placebo.

Statistically significant variations in side effects were seen between the nifedipine and progesterone groups in the present investigation. We found that nifedipine was more often associated with side effects than progesterone in our study. No one in our study had to discontinue taking their medication due to adverse effects or intolerance. However, Females in the nifedipine group reported feeling drowsy 16.7 percent of the time, compared to none in the progesterone group. Other side effects of nifedipine not seen in this study were nausea $(10 \%)$ and stomach discomfort (13.33\%). (3.33 percent). Progesterone use did not cause sleeplessness, weariness, headaches, or genital pain, as previously described [2, 9 and 12].

Recent studies have shown an association between nifedipine medication and some significant adverse effects. Severe maternal dyspnea, myocardial infarction, maternal hypoxia, and foetal death are only a few of the problems that may arise.. Six out of seven cases of nifedipine-related severe maternal dyspnea were detected in women who were pregnant with twins, according to a case study examination. People with poor cardiovascular function, however, should take nifedipine with caution. Nifedipine has a very low risk of serious adverse effects, less than one percent. Nifedipine has no effect on neonatal or foetal mortality, either [9].

There were no statistically significant changes in newborn respiratory distress between nifedipine and progesterone in this study. Progesterone was also less prevalent than nifedipine in this regard. Surfactanttreated infant RDS occurred in $12(6.0 \%)$ of 201 progesterone-treated pregnancies and $14(6.7 \%)$ of 205 nifedipine-treated pregnancies studied by AM.Abdelgaied et al.[1]. Vaginal progesterone medication, in comparison to nifedipine, was associated with a significant decrease in infant RDS, according to the findings of [19]. Nifedipine and 
progesterone groups, on the other hand, had no effect on the incidence of RDS.

This study also revealed that newborns in the progesterone group were 30 percent less likely to be hospitalised in the intensive care unit than those in the nifedipine group. When compared to nifedipine, which was related with reduced ICU admission rates and higher RDS occurrences, our data show that progesterone had no effect on newborn ICU admissions. However, D.Papatsonis et al.[17] reported that progesterone had no effect on neonatal ICU admissions ( 21 vs. 37 percent ; 0.46, 0.24, 0.89). The rate of infant ICU admissions and the length of stay in the neonatal ICU were not significantly different in a research comparing progesterone nifedipine to a placebo or no treatment[12]. This research also found that the newborn birth weight was greater in the progesterone group than in the nifedipine group, although the difference was not statistically significant. Three more studies reported similar results: the progesterone group had significantly lower mean foetal birth weights $(2.685456 \mathrm{~kg})$ than the non-nifedipine group $(2.856351 \mathrm{~kg})$, with no statistically significant difference.

A statistically significant difference was seen between the nifedipine and progesterone groups in terms of the severity of side effects, according to [18]. There was no statistical difference between the two groups when it comes to foetal birth weight. According to $[7,13]$, women who received progesterone were less likely to give birth before 37 weeks, have a baby weighing less than $2.5 \mathrm{~kg}$, or have a newborn diagnosed with intraventricular haemorrhage. However, these data contradict the conclusions of [7] and [13]. A statistically significant increase in birth weight was seen in the trial group over the placebo group, with birth weight ranging from 1.250 to 3.600 kilogrammes, with a mean of 2907 kilogrammes (3.026, 0.570 vs. $2.788,0.749$, respectively). It's possible that the differences in birth weight between the present research and the others might be attributed to the difference between progesterone in the threatening phase and tocolysis in established preterm labour.

To now, nifedipine has only been tested in comparisons with other drugs that mimic its effects, such as placebo. As far as newborn outcomes go, those in the nifedipine group had an average birth weight of 1,800 grammes, whereas those in the other trials ranged from 2,500 to 200 grammes [13]. Although the results of O'brien et al. [19] found a mean birth weight of $2,500 \mathrm{~g}$ in the progesterone group, ours came in at 3,100 g. [2].

\section{Conclusion}

For the most part, there is no correlation between nifedipine and vaginal progesterone. There are less negative effects with vaginal progesterone, making it a safer option. Acute tocolytic therapy with nifedipine was well tolerated by the majority of our patients, and no serious adverse effects necessitated discontinuing the medication. Progesterone suppositories with a daily dosage of $200 \mathrm{mg}$ were shown to extend the duration of pregnancy after a successful acute tocolysis. Nifedipine has a worse adverse effect than progesterone because of the way it is used.

\section{References}

[1] AM.Abdelgaied, RM.Dawood, AM.Nofal, EF.ElSisi, Comparison study between nifedipine and progesterone as maintenance tocolysis after arrested preterm labor. Menoufia Medical Journal .vol.32(2),pp.458,2019.

[2] S.Borna, N.Sahabi, Progesterone for maintenance tocolytic therapy after threatened preterm labour: a randomised controlled trial. Australian and New Zealand Journal of Obstetrics and Gynaecology .vil.48(1),pp.58-63,2008.

[3] S.Chawanpaiboon, K.Pimol, R.Sirisomboon, Comparison of success rate of nifedipine, progesterone, and bed rest for inhibiting uterine contraction in threatened preterm labor. Journal of Obstetrics and Gynaecology Research .vol.37(7),pp.787-791,2011.

[4] S.Chawanpaiboon, A.Sutantawibul, K.Pimol, R.Sirisomboon, S.Worapitaksanond, Preliminary study: comparison of the efficacy of progesterone and nifedipine in inhibiting threatened preterm labour in Siriraj Hospital. Thai Journal of Obstetrics and Gynaecology,pp.23-29,2009.

[5] A.Conde-Agudelo, R.Romero, K.Nicolaides, T.Chaiworapongsa, JM.O'Brien, E.Cetingoz, E.da Fonseca, G.Creasy, P.Soma-Pillay, S.Fusey, Vaginal progesterone vs cervical cerclage for the prevention of preterm birth in women with a sonographic short cervix, previous preterm birth, and singleton gestation: a systematic review and indirect comparison metaanalysis. American journal of obstetrics and gynecology 208(1).vol.42,pp.e1-42. e18,2013.

[6] M-X.Ding, X.Luo, X-M.Zhang, B.Bai, J-X.Sun, H-B.Qi, Progesterone and nifedipine for maintenance tocolysis after arrested preterm labor: A systematic review and meta-analysis of randomized controlled trial. Taiwanese Journal of Obstetrics and Gynecology.vol.55(3),pp.399404,2016.

[7] JM.Dodd, CA.Crowther, The role of progesterone in prevention of preterm birth. International journal of women's health .vol.1,pp.73,2009.

[8] E.Eldesouky, A.Farhan, O.Elsaid, E.Gaballah, Progesterone effect on cervical canal length between 16 and 34 weeks in gestation at high risk of preterm labor. AAMJ .vol.2,pp.297-318,2014.

[9] EB.Fonseca, E.Celik, M.Parra, M.Singh, KH.Nicolaides, Progesterone and the risk of preterm birth among women with a short cervix. New England Journal of Medicine.vol.357(5),pp.462-469,2007. 
[10] AMAL.Hak, HM.Gafaar, Effects of Nifedipine Therapy for Preterm Labor on Placental and Fetal Doppler Parameters in the First 24 Hours. The Medical Journal of Cairo University .vol.79(2),2011.

[11] S.Hassan, R.Romero, D.Vidyadhari, S.Fusey, J.Baxter, M.Khandelwal, J.Vijayaraghavan, Y.Trivedi, P.Soma- Pillay, P.Sambarey, Vaginal progesterone reduces the rate of preterm birth in women with a sonographic short cervix: a multicenter, randomized, double- blind, placebo- controlled trial. Ultrasound in Obstetrics \& Gynecology.vol.38(1),pp.18$31,2011$.

[12] S.Kamat, P.Veena, R.Rani, Comparison of nifedipine and progesterone for maintenance tocolysis after arrested preterm labour. Journal of Obstetrics and Gynaecology .vol.34(4),pp.322325,2014

[13] DJ.Lyell, KM.Pullen, J.Mannan, U.Chitkara, ML.Druzin, AB.Caughey, YY.El-Sayed, Maintenance nifedipine tocolysis compared with placebo: a randomized controlled trial. Obstetrics \& Gynecology.vol.112(6),pp.1221-1226,2008.

[14] TA.Nijman, GJ.van Baaren, EO.van Vliet, M.Kok, W.Gyselaers, MM.Porath, M.Woiski, MA.de Boer, KW.Bloemenkamp, M.Sueters, Cost effectiveness of nifedipine compared with atosiban in the treatment of threatened preterm birth (APOSTEL III trial). BJOG: An International Journal of Obstetrics \& Gynaecology .vol.126(7),pp.875-883,2019.

[15] S.Nisa, I.Chaudhry, H.Hanif, Comparison between Oral Nifedipine alone Vs Oral Nifedipine plus Progesterone as Tocolytic Agent in the Treatment of Threatened Preterm Labor. PJMHS .vol.27(4),pp.299-303,2016.

[16] J.O'brien, C.Adair, D.Lewis, D.Hall, E.Defranco, S.Fusey, P.Soma- Pillay, K.Porter, H.How,
R.Schackis, Progesterone vaginal gel for the reduction of recurrent preterm birth: primary results from a randomized, double- blind, placebo- controlled trial. Ultrasound in Obstetrics and Gynecology .vol.30(5),pp.687696,2007.

[17]D.Papatsonis, J.Kok, H.Van Geijn, O.Bleker, H.Ader, G.Dekker, Neonatal effects of nifedipine and ritodrine for preterm labor. Obstetrics \& Gynecology .vol.95(4),pp.477-481,2000.

[18] N.Rabei, M.Osama, A.Sultan, Comparison of the efficacy of progesterone and nifedipine in inhibiting threatened preterm labor: a randomized study. IJOGR .vol.5,pp.356-367,2016.

[19]R.Romero, K.Nicolaides, A.Conde-Agudelo, J.O'brien, E.Cetingoz, ED.Fonseca, G.Creasy, S.Hassan, Vaginal progesterone decreases preterm birth $<34$ weeks of gestation in women with a singleton pregnancy and a short cervix: an updated meta-analysis including data from the opptimum study. Buletin de perinatologie ,2017.

[20] NC.Sayin, FG.Varol, P.Balkanli-Kaplan, M.Sayin, Oral nifedipine maintenance therapy after acute intravenous tocolysis in preterm labor. Journal of Perinatal Medicine.vol.32(3) ,pp.41,2004.

[21] SH.Sharami, Z.Zahiri, M.Shakiba, F.Milani, Maintenance therapy by vaginal progesterone after threatened idiopathic preterm labor: a randomized placebo-controlled double-blind trial. Int J Fertil Steril .vol.4,pp.45-50,2010.

[22] A.Shumaila, S.Nargis, H.Gulfishan, Role of Nifedipine in Preterm Labour. Pakistan Journal of Surgery .vol.26(3),pp.226-231,2010.

[23] S.Songthamwat, CN.Nan, M.Songthamwat, Effectiveness of nifedipine in threatened preterm labor: a randomized trial. International journal of women's health .vol.10,pp.317,2018. 